\title{
BDA pays tribute to HRH the Duke of Edinburgh 1921-2021
}

The British Dental Association (BDA) paid tribute to its past President, His Royal Highness the Duke of Edinburgh, following the news of his death on 9 April 2021.

The Duke was made an honorary member of the BDA in 1957 and remained a constant supporter of the Association's work. In 1980 he was appointed President of Honour, marking the centenary of the BDA.

Writing in his Presidential address in 1980, the Duke wrote: 'If the Association feels that a hundred years is worth celebrating, I can only say that millions of dental patients will join them in their celebration, if only in thanksgiving for the vast improvement and progress in dental treatment that has taken place in that period and for the development of the concept of prevention as of equal importance to treatment'.

The Association has extended its condolences to Her Majesty the Queen, the Association's Royal Patron.

BDA President Russ Ladwa said: 'The BDA has lost an honorary member, a past President, and a firm believer in the role dentists play in improving the health of the nation.

'Over 40 years ago the Duke set out a vision on prevention that was ahead of its time and remains our goal.

'The Association salutes the foresight of my predecessor, and on behalf of this profession let me extend our condolences to our Patron, Her Majesty the Queen, and to the Royal Family.

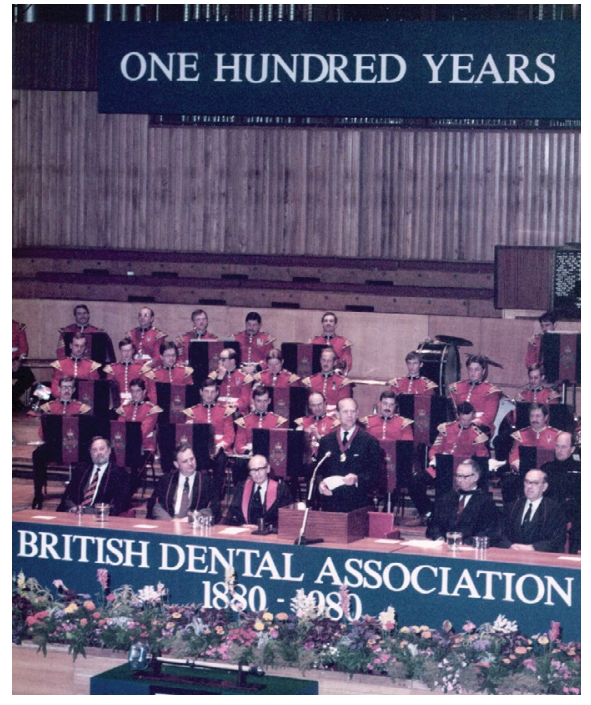

The Duke of Edinburgh's Presidential address in 1980

\section{The mental health of Welsh dentists during the pandemic}

\section{By Christie Owen, BDA Wales}

The mental health and wellbeing of dentists is a priority for the British Dental Association (BDA). Over the course of the COVID-19 pandemic, BDA members raised concerns over the increased levels of stress that dentists are dealing with daily. We designed a survey to capture the mental health impacts the pandemic has had on all dentists working in Wales, and the different sources of stress that they face. A full research paper will be submitted to the $B D J$ in the coming months and we would like to share some of the initial results.

Carrying out NHS work in the pandemic is stressful for dentists in Wales, with over half of respondents finding this 'extremely stressful' or 'very stressful'. When considering the survey findings, it is important to remember the shift in perception the pandemic has created. What may have been deemed highly stressful prior to the pandemic may be seen as less stressful, particularly in comparison to others, including the stresses COVID-19 has brought to daily life outside of work.

Working in Urgent Dental Care centres (UDCs) has caused significant stress: 62\% of respondents found working in UDCs 'extremely stressful' or 'very stressful'. Finances were also a source of stress; over half the GDS respondents reported to be extremely stressed by the finances of their practice, while $93 \%$ were at least moderately stressed. Worryingly, $43 \%$ of dentists could not cope with the level of stress in their job.

No respondents reported their sleep quality as very bad prior to the pandemic; however, during the pandemic, this has risen to $18 \%$. Almost two thirds of respondents working in the GDS rated their sleep quality as bad or very bad. Over $80 \%$ of dentists thought the pandemic had impacted the quality or duration of their sleep.

Activity levels have significantly declined, with a $20 \%$ drop in those meeting or exceeding the recommended 150 minutes of moderate-intensity activity or 75 minutes of vigorous-intensity activity.

The survey also looked at the use of substances. Results showed that $39 \%$ of dentists are drinking alcohol more frequently than before the pandemic; this was the most reported description of alcohol use during the pandemic. Of those dentists who use nicotine products, including cigarettes, e-cigarettes, and cigars, almost two thirds use them more frequently than before the pandemic. Most dentists have also been using positive coping methods such as going for walks, practising yoga, gardening, and meditation.
Dentists gave an insight into their pandemic working conditions. Over one third are unable to take at least half an hour lunch break most working days. One dentist commented 'When I went back to work in July no breaks whatsoever in full PPE all session?

Many dentists have observed a rise in administrative tasks and time needed for triaging, and $96 \%$ of respondents were concerned with the rising levels of patient backlog.

Staff are physically and mentally exhausted; $82 \%$ of respondents said stress levels in the dental team have increased noticeably. Three quarters of respondents have gone to work on one or more days, despite not feeling mentally well enough. It is alarming that more than half of respondents in this group have done so for more than ten days.

The pandemic has brought challenges to all aspects of dentistry and the impacts are still being experienced. Our survey uncovers a great deal of stress as a result of the pandemic, and concerns for the future of dentistry in Wales. The upcoming research paper will discuss the results in greater detail as well as possible solutions. 